\title{
Influence of endothelial nitric oxide synthase gene SNPs in the delayed cardiopulmonary transition of premature infants
}

\author{
Krishna Yanamandra $^{1 *}$ Sushil K. Jain ${ }^{1}$ Arun Pramanik ${ }^{1}$, Joseph A. Bocchini Jr. ${ }^{1}$ and Ramasubbareddy Dhanireddy ${ }^{2}$ \\ ${ }^{1}$ Department of Pediatrics, LSU Health Sciences Center, Shreveport, LA, USA \\ ${ }^{2}$ Department of Pediatrics, UT Health Science Center, Memphis, TN, USA
}

\begin{abstract}
Objective: The present investigation was undertaken to study the role of eNOS gene polymorphisms in the etiology of pulmonary abnormalities in premature neonates.

Study design: Genotypes T-786C and G894T in the eNOS gene SNPs were studied in two hundred and eighty five infants from NICU facility by microplate-RFLP PCR method.

Results: Our data showed significant differences in baseline eNOS gene frequencies between Caucasian and African American infants. Significantly higher mutant SNP frequencies in infants with delayed cardiopulmonary transition requiring ventilation compared to race matched controls were observed in both the African American and Caucasian ethnicities.

Conclusions: The present data suggest that there is a significant association between the disease and the eNOS SNPs suggesting that these premature neonates may be benefited by prior genotype screening so that it may help in treating these infants with inhaled NO and hasten the cardiopulmonary transition and thereby decrease their NICU stay.
\end{abstract}

\section{Introduction}

Physiologic transition for the neonate following birth is highly dependent upon a series of complex events as elegantly demonstrated by experimentation in sheep and lamb [1-3]. Barclay's [1] experiments have shown the events of dutus arteriosus, ductus venosus, and formen ovale closures that follow immediately after birth. Research by Dawes, et al. [2] have shown the fall of pulmonary vascular resistance by as much as $90 \%$ during the artificial positive pressure ventilation. They observed a large decrease of pulmonary vascular resistance when the lungs were expanded with air, oxygen, or nitrogen, but not when they were expanded with saline. This is a pivotal experiment to show that when the infant was delivered at the time of birth, the first breaths of the infant evacuate the lungs that were filled with fluid during fetal stage, and decreases pulmonary resistance greatly. However, failure to evacuate the fetal lung fluid in premature infants either to hypoxia or persistent pulmonary resistance could result in delayed cardiopulmonary transistion. Prior to birth, the fetus is dependent on the maternal-placental circulation for oxygen, nutrients, and waste removal. Prenatally, the fetal lungs are fluid filled and low amplititude "breathing" movements occur. The fetal cardiopulmonary circulation is characterized by blood flow through a series of vascular shunts and cardiac structures. Beginning at the level of placenta, nutrient- and oxygen-rich fetal blood flows through the umbilical vein and ductus venosus into the right atrium. Most of this blood is diverted through the foramen ovale and passes from the left atrium, left ventricle, and aorta to supply the heart, brain, and right upper extremity with the most well-oxygenated and nutrient-dense blood from the placenta.
Blood that has travelled through the brain and other body organs returns to the right atrium by way of the superior and inferior venacava. This carbon dioxide/waste-rich and oxygen/nutrient-depleted blood in the right atrium is directed into the right ventricle/pulmonary artery to be diverted across the ductus arteriosus into the descending aorta. The diversion of blood flow from the right ventricle through ductus arteriosus occurs because of high pulmonary vascular resistance generated in the fetus by active pulmonary vasoconstriction. In the aorta distal to the ductus arteriosus, blood supplying the rest of the body is a mixture of oxygen/nutrient-rich and depleted blood, most of which flows through the umblical arteries back to the placenta.

After birth, the series circulatory pattern of the fetus must transition to the parallel circulatory pattern that characterizes the normal neonate, child, and adult. This transition rapidly progresses with the onset of breathing. Normal cardiopulmonary transition after birth requires clearance of fetal lung fluid from alveoli and an increase in pulmonary blood flow. With the first breaths, fluid within the airways and alveoli is forced into the lung tissue where it is absorbed and

Correspondence to: Krishna Yanamandra. Ph.D., FACMG, Associate Professor, Director of Biochemical \& Molecular Genetics Laboratory Department of Pediatrics, LSU Health Sciences Center 1501 Kings Hwy Shreveport, LA 71103, USA, Tel: 318-675-5896 Fax: 318-675-4669 E-mail: kyanam@lsuhsc.edu

Key words: endothelial nitric oxide synthase, single nucleotide polymorphism, delayed cardiopulmonary transition, nitric oxide, premature infants

Received: May 04, 2017; Accepted: May 22, 2017; Published: May 25, 2017 
carried away from the lungs by the lymphatics and pulmonary veins. Fluid within the alveoli is replaced with air. Oxygen diffuses into the blood raising arterial $\mathrm{PO}_{2}$ and leading to relaxation of the pulmonary arterioles. Separation of the placenta results in loss of the low-resistance placental circulation and is accompanied by an increase in systemic vascular resistance. A fall in pulmonary vascular resistance following the onset of ventilation results in increased pulmonary blood flow, improved oxygenation, and increased blood pressure in the left atrium. Right atrial pressure falls with loss of blood flow from the umbilical vein/ductus venosus associated with placental separation and ductus venosus closure. With increased left atrial pressure and lower right atrial pressure, the foramen ovale functionally closes. An increase in oxygen tension in blood flowing through the ductus arteriosus from approximately $30 \mathrm{~mm} \mathrm{Hg}$ in the fetus to $80 \mathrm{~mm} \mathrm{Hg}$ in the newly born infant triggers functional closure of the ductus arteriosus. Therefore, the fall in pulmonary vascular resistance sets in motion a number of rapidly evolving physiological changes that close the ductus venosus, foramen ovale, and ductus arteriosus, effecting separation of the pulmonary and systemic circuits into parallel circulations. These transitions predominantly occur during the first minutes to hours of life with completion by 2 to 4 weeks of age.

Clearance of fluid from the lungs at the time of birth is enhanced by labor prior to delivery and is facilitated with effective initial breaths. Infants who are apneic at birth or those with shallow, ineffective respirations have impaired clearance of fluid. Apnea and ineffective respiration are common clinical findings in preterm infants and infants who have experienced a peripartum hypoxic insult. Failure to clear fluid from the lungs delays normal cardiopulmonary transition and may result in transient tachypnea of the newborn (TTN). Many pathophysiological events will delay the normal fall in pulmonary vascular resistence, impairing the increase in pulmonary blood flow and resulting in failure of closure of the foramen ovale and ductus arteriosus. Continued admixture of pulmonary and systemic circulations through these open channels maintains fetal hypoxemic levels. This inability to effect a fall in pulmonary vascular resistance is termed persistent pulmonary hypertension of the newborn (PPHN), a common pathophysiologic pathway in many diseases that compromise the pulmonary and cardiac systems of newly born infants.

Pathophysiology of asphyxia: Asphyxia occurs when there is impairement of function within the organ of gas exchange. In the fetus, asphyxia results from decreased placental blood flow or maternal hypoxia. In the newly born infant, asphyxia occurs either when there is alveolar hypoventilation or impaired pulmonary blood flow. During the process of asphyxia, oxygen concentration falls and carbon dioxide increases in the bloodstream. The $\mathrm{pH}$ falls as a result of the increase in PCO2 (respiratory acidosis) as well as the accumulation of organic acids (metabolic acidosis).

The initial fetal response to hypoxemia includes a vigorous effort to breathe with preservation of heart rate and blood pressure. If hypoxemia continues, primary apnea with bradycardia but preservation of blood pressure follows. It is important to recognize that the sequence of these events begin in utero and continue after delivery.

Anticipation of High risk for neonatal resuscitation in newly born infants: Antepartum factors include: Chronic maternal illness, Pregnancy-induced hypertension, Isoimmu-nization, Bleeding or anemia, Prior fetal or neonatal death, Preterm or postterm gestation, Premature rupture of membranes, Maternal infection, Multiple gestation, Intrauterine growth restriction, Fetal macrosomia,
Fetal malformation, Diminished fetal activity, Polyhydramnios or Oligohydramnios, Abruptio placenta or placenta previa.

Intrapartum factors include: Emergency cesarean, forceps, or vacuum-assisted delivery, Abnormal presentation, Abnormal labor: premature, prolonged, or precipitous, Chorioamnionitis, Prolonged rupture of membranes, Fetal heart rate abnormalities, General anesthesia, Uterine tetany, Maternal narcotics $<4 \mathrm{~h}$ before delivery Mecomium-stained amniotic fluid, Umblical cord prolapsed.

Earlier studies have established that the fetal lung itself, rather than the amniotic sac, is the source of the liquid that fills the lung during development. This liquid forms a slowly expanding structural template that prevents collapse and promotes growth of the fetal lungs. Rapid clearance of liquid from potential airspaces during and soon after birth is essential for establishing the timely switch from placental to pulmonary gas exchange [4-7].

As a result of this delayed transition, premature infants experience a great deal of respiratory distress. Pharmacological inhaled nitric oxide and or L-Arginine along with supplemental oxygen is instituted frequently to reduce the distress and to facilitate the improved vasculature in those infants [8-13]. Endothelial nitric oxide (eNO) serves as a vasodilator, relaxes smooth muscle, prevents platelet aggregation, and facilitates improved blood flow, leading to vascular homeostatsis. Reduced nitric oxide levels result in vasoconstriction and weak tone leading to decreased blood flow and hypoxia. Mutant eNO synthetase (eNOS) genotypes result in reduced nitric oxide levels by decreasing the enzyme activity [14-17]. Although several studies have been carried out with NO, polymorphic studies at gene level were limited at best. Our earlier studies [18-20] in adult asthmatics, as well as other polymorphisms in NICU infants have paved the way to address the role of eNOS genotypes during respiratory distress in premature infants.

\section{Methods}

\section{Patients and controls}

Peripheral blood samples from two hundred and eighty five (one hundred fifty four infants underwent supplemental $\mathrm{O}_{2}$ requirement, and one hundred and thirty one infants did not require supplemental gas) premature infants from LSUHSC, Shreveport, Louisiana, pediatric NICU facility were collected consecutively.

\section{Methods}

Two eNOS gene single nucleotide polymorphisms (SNPs) (T-786C, and G894T) were studied by microplate-RFLP PCR method.

\section{DNA isolation}

DNA was isolated from patients and control samples using the QAIGEN DNA isolation kits.

\section{Genotyping T-786C SNP assay}

Genotyping assay [14] was modified to suit the large number of samples in our laboratory. Briefly, micro plate PCR-RFLP assay was carried out in 10 micro liters with1 micro liter DNA, $3.25 \mathrm{mM} \mathrm{MgCl} 2$, $0.375 \mathrm{mM}$ dNTP mix, 10 X PCR reaction buffers II, 1 unit of Gold Taq polymerase from Applied Biosystems Corp., 0.015 micro molar primer mix with the following sequences:

\section{F: TGG AGA GTG CTG GTG TAC CCC A}

R: GCC TCC ACC CCC ACC CTG TC 
The following PCR parameters were used: Initial denaturation for $10 \mathrm{~min}$ at $940 \mathrm{C}, 35 \mathrm{cycles}$ of $940 \mathrm{C}$ for $30 \mathrm{sec}, 640 \mathrm{C}$ for $30 \mathrm{sec}$, and $720 \mathrm{C}$ for $60 \mathrm{sec}$., with the last extension at $720 \mathrm{C}$ for $5 \mathrm{~min}$.

Following PCR, the 180bp product was digested by 2 units of Msp 1 restriction enzyme from New England Biolabs, with 1.2 micro liters of 10X Msp 1 buffer, at 370C for 2 hours. Msp 1 digested PCR fragments were separated by electrophoresis on $2 \%$ agarose gel for 3 hours.

Scoring of eNOS T-786C genotypes: Genotypes were scored as follows: TT homozygotes with $140 \mathrm{bp}, 40 \mathrm{bp}$; CC homozygotes with 90bp, 50bp, 40bp; TC heterozygotes with 140bp, 90bp, 50bp, 40bp, electrophoretic bands using UV-fluorography and ethidium bromide staining.

Genotypes were stratified according to the ethnicities, preterm and full term, and prematurity conditions.

\section{Genotyping eNOS G894T (Glu298Asp) SNP assay}

PCR composition is similar to the T-786C assay, except for the primer sequence which is as follows:

\section{F: AAG GCA GGA AGT GGA TGG A}

\section{R: CCC AGT CAA TCC CTT TGG TGC TCA}

PCR conditions are as follows: Initial denaturation at $94 \mathrm{C}$ for 10 min, followed by 35 cycles of $94 \mathrm{C}$ for $30 \mathrm{sec}, 63 \mathrm{C}$ for $30 \mathrm{sec}, 72 \mathrm{C}$ for $60 \mathrm{sec}$, with a final extension of $72 \mathrm{C}$ for $5 \mathrm{~min}$. Following the PCR, the 258bp product was digested for $2 \mathrm{hrs}$ at 37C with Ban II restriction enzyme, and electrophoresed on $2 \%$ agarose gel for $1.5 \mathrm{hrs}$. Scoring of G894T genotypes: Genotype 894GG with bands of 163bp, 85bp; genotype $894 \mathrm{TT} 258 \mathrm{bp}$, and the heterozygote $894 \mathrm{GT} 258 \mathrm{bp}, 163 \mathrm{bp}$, 85bp. Genotypes are stratified according to the ethnicity, preterm, full term, and prematurity conditions.

\section{Results}

Baseline gene frequencies of both the SNPs in the control infants differed significantly between African Americans and Caucasians (Tables 1). Caucasian infants displayed significantly 2.5-fold higher frequencies of mutant SNPs compared to African Americans, odds ratio 4, (95\% CI 1.9-8.4, $\mathrm{p}=<0.001$, for T-786C; odds ratio $2.3(95 \%$ CI 1-5.3, $\mathrm{p}=<0.05$ ), for G894T; and odds ratio 3.1, (95\% CI 1.8 $5.4, \mathrm{p}=<0.001)$ for the combined SNPs. Baseline mean and median gestational ages and birth weights were not significantly different in patients and controls of either ethnicity (data not shown). SNP data on the two markers in infants with and without delayed cardiopulmonary transition in Caucasians are presented in Table 2, and in African Americans in Table 3.

In Caucasian infants, -786C allele, and 894T allele were 2-fold higher among the infants with delayed cardiopulmonary transition compared to those without, odds ratio 2.9 , (95\% CI $1.1-4, \mathrm{p}=<0.001)$. Similarly in the African American infants, with delayed cardiopulmonary transition, two mutant SNPs allele frequencies were 3-fold higher compared to those without, odds ratio 3, (95\% CI 1.8-5, $\mathrm{p}=<0.001)$.

\section{Discussion}

The present data indicate the need for ethnic stratification because of the significant differences in the SNP genotype and allele frequencies between African American and Caucasian infants. We have demonstrated that the mutant $-786 \mathrm{C}$ and $894 \mathrm{~T}$ alleles were significant risk factors in the premature infants with delayed cardiopulmonary transition. This association was similar in both the Caucasian and African American premature infants. Earlier reports have shown that the mutant eNOS alleles lead to significant drop in the endogenous production of NO levels.

Inhaled nitric oxide (iNO) treatment as a therapeutic intervention has been suggested in persistent pulmonary hypertension of newborn

Table 1. Distribution of T-786C and G894T genotypes and alleles in Caucasian and African American control infants.

\begin{tabular}{|c|c|c|c|c|c|c|}
\hline & Caucasians & Caucasians & African Americans & African Americans & OR (95\%CI) & pValue \\
\hline Markers & $\#$ & Freq & $\#$ & Freq & Caucasians vs. & \\
\hline T786C Genotypes & & & & & African Americans & \\
\hline $\mathrm{CC}$ & 4 & 0.09 & 1 & 0.01 & & \\
\hline $\mathrm{TC}$ & 14 & 0.3 & 10 & 0.12 & & \\
\hline TT & 29 & 0.61 & 73 & 0.87 & & \\
\hline Total & 47 & 1 & 84 & 1 & & \\
\hline $\mathrm{C}$ & 22 & 0.23 & 12 & 0.07 & $4(1.9-8.4)$ & $<0.001$ \\
\hline $\mathrm{T}$ & 72 & 0.77 & 156 & 0.93 & & \\
\hline Total Alleles & 94 & 1 & 168 & 1 & & \\
\hline \multicolumn{7}{|l|}{ G894T } \\
\hline TT & 1 & 0.02 & 1 & 0.01 & & \\
\hline GT & 11 & 0.23 & 9 & 0.11 & & \\
\hline GG & 35 & 0.75 & 74 & 0.88 & & \\
\hline Total & 47 & 1 & 84 & 1 & & \\
\hline $\mathrm{T}$ & 13 & 0.14 & 11 & 0.07 & $2.3(1-5.3)$ & $<0.05$ \\
\hline $\mathrm{G}$ & 81 & 0.86 & 157 & 0.94 & & \\
\hline Total Alleles & 94 & 1 & 168 & 1 & & \\
\hline $\begin{array}{c}\text { CombinedGenotypes } \\
\text { CC/TT }\end{array}$ & 5 & 0.05 & 2 & 0.01 & & \\
\hline $\mathrm{TC} / \mathrm{GT}$ & 25 & 0.27 & 19 & 0.11 & & \\
\hline TT/GG & 64 & 0.68 & 147 & 0.88 & & \\
\hline Total & 94 & 1 & 168 & 1 & & \\
\hline $\mathrm{C} / \mathrm{T}$ & 35 & 0.19 & 23 & 0.07 & $3.1(1.8-5.4)$ & $<0.001$ \\
\hline $\mathrm{T} / \mathrm{G}$ & 153 & 0.81 & 313 & 0.93 & & \\
\hline Total Alleles & 188 & 1 & 336 & 1 & & \\
\hline
\end{tabular}


Table 2. Distribution of T-786C and G894T genotypes and alleles in Caucasian Delayed ardiopulmonary transition (DCPT) cases and controls.

\begin{tabular}{|c|c|c|c|c|c|c|}
\hline Caucasians & DCPT & DCPT & Controls & Controls & OR $(95 \% C I)$ & pValue \\
\hline Marker & $\#$ & Freq & \# & Freq & & \\
\hline \multicolumn{7}{|l|}{ T786C Genotypes } \\
\hline $\mathrm{CC}$ & 10 & 0.11 & 4 & 0.09 & & \\
\hline $\mathrm{TC}$ & 52 & 0.59 & 14 & 0.3 & & \\
\hline TT & 26 & 0.30 & 29 & 0.61 & & \\
\hline Total Genotypes & 88 & 1.00 & 47 & 1 & & \\
\hline $\mathrm{C}$ & 72 & 0.41 & 22 & 0.23 & $2.3(1.3-4)$ & $<0.004$ \\
\hline $\mathrm{T}$ & 104 & 0.59 & 72 & 0.77 & & \\
\hline Total Alleles & 176 & 1.00 & 94 & 1 & & \\
\hline \multicolumn{7}{|l|}{ G894T Genotypes } \\
\hline $\mathrm{TT}$ & 10 & 0.11 & 1 & 0.02 & & \\
\hline GT & 47 & 0.53 & 11 & 0.23 & & \\
\hline GG & 31 & 0.35 & 35 & 0.75 & & \\
\hline Total Genotypes & 88 & 1.00 & 47 & 1 & & \\
\hline $\mathrm{T}$ & 67 & 0.38 & 13 & 0.14 & $3.8(2-7.4)$ & $<0.001$ \\
\hline G & 109 & 0.62 & 81 & 0.86 & & \\
\hline Total Alleles & 176 & 1.00 & 94 & 1 & & \\
\hline \multicolumn{7}{|l|}{ Combined Genotypes } \\
\hline $\mathrm{CC} / \mathrm{TT}$ & 20 & 0.11 & 5 & 0.05 & & \\
\hline $\mathrm{TC} / \mathrm{GT}$ & 99 & 0.56 & 25 & 0.27 & & \\
\hline TT/GG & 57 & 0.32 & 64 & 0.68 & & \\
\hline Total Genotypes & 176 & 1.00 & 94 & 1 & & \\
\hline $\mathrm{C} / \mathrm{T}$ & 139 & 0.40 & 35 & 0.19 & $2.9(1.9-4.3)$ & $<0.001$ \\
\hline $\mathrm{T} / \mathrm{G}$ & 213 & 0.61 & 153 & 0.81 & & \\
\hline Total Alleles & 352 & 1.00 & 188 & 1 & & \\
\hline
\end{tabular}

Table 3. Distribution of T-786C and G894T genotypes and alleles in African American Delayed Cardiopulmonary transition (DCPT) cases and controls.

\begin{tabular}{|c|c|c|c|c|c|c|}
\hline African Americans & DCPT & DCPT & Controls & Controls & OR $(95 \%$ CI) & pValue \\
\hline Marker & $\#$ & Freq & \# & Freq & & \\
\hline \multicolumn{7}{|l|}{ T786C Genotypes } \\
\hline $\mathrm{CC}$ & 3 & 0.05 & 1 & 0.01 & & \\
\hline $\mathrm{TC}$ & 23 & 0.35 & 10 & 0.12 & & \\
\hline $\mathrm{TT}$ & 40 & 0.61 & 73 & 0.87 & & \\
\hline Total Genotypes & 66 & 1.00 & 84 & 1 & & \\
\hline $\mathrm{C}$ & 29 & 0.22 & 12 & 0.07 & $3.7(1.8-7.4)$ & $<0.001$ \\
\hline $\mathrm{T}$ & 103 & 0.78 & 156 & 0.93 & & \\
\hline Total Alleles & 132 & 1.00 & 168 & 1 & & \\
\hline \multicolumn{7}{|l|}{ G894T Genotypes } \\
\hline $\mathrm{TT}$ & 0 & 0 & 1 & 0.01 & & \\
\hline GT & 19 & 0.29 & 9 & 0.11 & & \\
\hline GG & 47 & 0.71 & 74 & 0.88 & & \\
\hline Total Genotypes & 66 & 1.00 & 84 & 1 & & \\
\hline $\mathrm{T}$ & 19 & 0.14 & 11 & 0.07 & $2.4(1.1-5.2)$ & $<0.025$ \\
\hline G & 113 & 0.86 & 157 & 0.94 & & \\
\hline Total Alleles & 132 & 1.00 & 168 & 1 & & \\
\hline \multicolumn{7}{|l|}{ Combined Genotypes } \\
\hline $\mathrm{CC} / \mathrm{TT}$ & 3 & 0.02 & 2 & 0.01 & & \\
\hline $\mathrm{TC} / \mathrm{GT}$ & 42 & 0.32 & 19 & 0.11 & & \\
\hline TT/GG & 87 & 0.66 & 147 & 0.88 & & \\
\hline Total Genotypes & 132 & 1.00 & 168 & 1 & & \\
\hline $\mathrm{C} / \mathrm{T}$ & 48 & 0.18 & 23 & 0.07 & $3(1.8-5)$ & $<0.001$ \\
\hline $\mathrm{T} / \mathrm{G}$ & 216 & 0.82 & 313 & 0.93 & & \\
\hline Total Alleles & 264 & 1.00 & 336 & 1 & & \\
\hline
\end{tabular}

cases as reported by Cook and Stewart [8] and in severe hypoxic respiratory failure. Several investigators have reported the utility of L-Arginine supplementation in treating infants with necrotizing enterocolitis. Our data suggests that the genotypes in premature infants may influence the cardiopulmonary transition. The genetic NOS status of the infant reveals endogenous production in the infant. Thus, we speculate that depending upon the infant genotype, inhaled NO or L-Arginine dosage regimen can be adjusted to prevent catastrophic damage by excess treatment [21]. Furthermore, eNOS SNP testing in infants born prematurely, particularly those with delayed cardiopulmonary transition is warranted. 


\section{Acknowledgements}

This study was undertaken by intramural funding of LSU Health Sciences Center. The authors gratefully acknowledge the expert technical assistance provided by Ms. Dawn Napper in Biochemical and Molecular Genetics Laboratory of LSU Health Sciences Center, Shreveport, Louisiana.

\section{Disclosure}

Preliminary studies have been presented at the Pediatric Academic Societies annual meeting, Baltimore, MD, May 2-5, 2009.

\section{Conflicts of interest}

The authors do not have any conflict of interests.

\section{References}

1. Barclay AE, Barcroft J, Barron DH, Franklin KJ, Prichard MML (1941) Studies of the foetal circulation and of certain changes that take place after birth. Amer J Anat 69: 383-406.

2. Dawes GS, Mott JC, Widdicombe JG, Wyatt DG (1953) Changes in the lungs of the new-born lamb. J Physiol 121: 141-162. [Crossref]

3. Abman SH, Chatfield BA, Hall SL, McMurtry IF (1990) Role of endothelium-derived relaxing factor during transition of pulmonary circulation at birth. Amer J Physiol 259: H1921-H1927. [Crossref]

4. Bland RD (2005) Lung fluid balance during development. NeoReviews 6: e255-e267.

5. Alcorn D, Adamson TM, Lambert TF, Maloney JE, Ritchie BC, Robinson PM (1977) Morphological effects of chronic tracheal ligation and drainage in the fetal lamb lung. $J$ Anat 123: 649-660. [Crossref]

6. Harding R, Hooper SB (1996) Regulation of lung expansion and lung growth before birth. J Appl Physiol (1985) 81: 209-224. [Crossref]

7. Moessinger AC, Harding R, Adamson TM, Singh M, Kiu GT (1990) Role of Lung fluid volume in growth and maturation of the fetal sheep lung. J Clin Invest 86: 1270-1277. [Crossref]

8. Cook LN, Stewart DL (2005) Inhaled nitric oxide in the treatment of persistent pulmonary hypertension/ hypoxic respiratory failure in neonates: an update. $J \mathrm{Ky} \mathrm{Med}$ Assoc 103: 138-147. [Crossref]
9. Chotigeat U, Khorana M, Kanjanapattanakul W (2007) Inhaled nitric oxide in newborns with severe hypoxic respiratory failure. J Med Assoc Thai 90: 266-271. [Crossref]

10. Di Lorenzo M, Bass J, and Krantis A (1995) Use of L-Arginine in the treatment of experimental necrotizing enterocolitis. J Pediatr Surg 30: 235-240. [Crossref]

11. Neu J (2007) Arginine supplementation for neonatal necrotizing enterocolitis: are we ready? Br J Nutr 97: 814-815. [Crossref]

12. Richir MC, Siroen MPC, van Elburg RM, Fetter WP, Ouik F, et al. (2007) Low plasma concentrations of arginine and asymmetric dimethylarginine in premature infants with necrotizing enterocolitis. Br J Nutr 97: 906-911. [Crossref]

13. Shah PS, Shah VS (2007) Arginine supplementation for prevention of necrotizing enterocolitis in preterm infants. Cochrane Database Syst Rev 3: CD004339. [Crossref]

14. Tsukada T, Yokoyama K, Arai T, Takemoto F, Hara S, et al. (1998) Evidence of association of the ecNOS gene polymorohism with plasma NO metabolite levels in humans. Biochem Biophys Res Commun 245: 190-195. [Crossref]

15. Yoon Y, Song J, Hong SO, Kim JQ (2000) Plasma nitric oxide concentrations and nitric oxide synthase gene polymorphisms in coronary artery disease. Clin Chem 46 : 1626-1630. [Crossref]

16. Song J, Yoon Y, Park KU, Park J, Hong YJ, et al. (2003) Genotype-specific influence on nitric oxide synthase gene expression, protein concentrations, and enzyme activity in cultured human endothelial cells. Clin Chem 49: 847-852. [Crossref]

17. Ahluwalia TS, Ahuja M, Rai TS, Kohli HS, Sud K, et al. (2008) Endothelial nitric oxide synthase gene haplotypes and diabetic nephropathy among Asian Indians. Mol Cell Biochem 314: 9-17. [Crossref]

18. Yanamandra K, Boggs PB, Thurmon TF, Lewis D, Bocchini Jr. JA, Dhanireddy R (2005) Novel allele of the endothelial nitric oxide synthase gene polymorphism in caucasian asthmatics. Biochem Biophys Res Commun 335: 545-549. [Crossref]

19. Dhanireddy R, Boggs P, Yanamandra K, Napper D, Chen H, et al. (2005) Association of endothelial nitric oxide synthase gene (ecNOS) haplotype with asthma in the caucasians. Genet Med 7: A57.

20. Ursin SA, Yanamandra K, Boggs P, Napper D, Thurmon TF, et al. (2005) Ethnic differences in distribution of important asthma-associated polymorphisms. Genet Med 7: A64.

21. Yanamandra K, Vannemreddy P, Napper D, Pramanik A, Bocchini Jr. JA, et al (2009) Mutant eNOS genotypes lead to delayed cardiopulmonary transition and need for supplemental O2 therapy in premature infants. Paper presented at the Pediatric Academic Societies (PAS) annual meeting held May 2-May 5, 2009, at Baltimore, USA.

Copyright: (C2017 Yanamandra K. This is an open-access article distributed under the terms of the Creative Commons Attribution License, which permits unrestricted use, distribution, and reproduction in any medium, provided the original author and source are credited. 